\title{
BMJ Open Association between QTc prolongation and mortality in patients with suspected poisoning in the emergency department: a transnational propensity score matched cohort study
}

\author{
Camilla Schade Hansen, ${ }^{1}$ Anton Pottegård, ${ }^{2}$ Ulf Ekelund, ${ }^{3}$ \\ Helene Kildegaard Jensen, ${ }^{1}$ Jakob Lundager Forberg, ${ }^{4}$ Mikkel Brabrand, ${ }^{1,5}$ \\ Annmarie Touborg Lassen ${ }^{1}$
}

To cite: Schade Hansen $\mathrm{C}$, Pottegård $\mathrm{A}$, Ekelund $\mathrm{U}$, et al. Association between QTC prolongation and mortality in patients with suspected poisoning in the emergency department: a transnational propensity score matched cohort study. BMJ Open 2018;8:e020036. doi:10.1136/ bmjopen-2017-020036

- Prepublication history and additional material for this paper is available online. To view these files please visit the journal online (http://dx.doi.org/10. 1136/bmjopen-2017-020036).

Received 21 October 2017 Revised 17 March 2018 Accepted 16 May 2018

Check for updates

${ }^{1}$ Department of Emergency Medicine, Odense University Hospital, Odense, Denmark ${ }^{2}$ Clinical Pharmacology and Pharmacy, Department of Public Health, University of Southern Denmark, Odense, Denmark

${ }^{3}$ Department of Emergency Medicine, Skåne University Hospital, Lund, Sweden ${ }^{4}$ Department of Emergency Medicine, Helsingborg Hospital, Helsingborg, Sweden

${ }^{5}$ Department of Emergency Medicine, Hospital of South West Jutland, Esbjerg, Denmark

Correspondence to

Camilla Schade Hansen;

camilla.schade.hansen@rsyd.dk

\section{ABSTRACT}

Objectives Poisoning is a frequent cause of admission to the emergency department (ED) and may involve drugs known to prolong the QT interval. This study aims to describe the prevalence of QTc prolongation among ED patients with suspected poisoning and to calculate the absolute and relative risk of mortality or cardiac arrest associated with a prolonged QTC interval.

Methods We performed a register-based cohort study, including all adult first-time contacts with suspected poisoning to the ED of two Swedish hospitals (January 2010-December 2014) and two Danish hospitals (March 2013-April 2014). We used propensity score matching to calculate HRs for all-cause mortality or cardiac arrest (combined endpoint) within 30 days after contact comparing patients with a prolonged QTc interval ( $\geq 450 \mathrm{~ms}$ men, $\geq 460 \mathrm{~ms}$ women) with patients with a QTC interval of $<440 \mathrm{~ms}$.

Results Among all first-time contacts with suspected poisoning that had an ECG recorded within 4 hours after arrival $(n=3869)$, QTc prolongation occurred in $6.5 \%$. The overall mortality after a 30 -day follow-up period was $0.8 \%$ (95\% Cl 0.6 to 1.2), with an absolute risk of mortality or cardiac arrest in patients with QTc prolongation of $3.2 \%$ (95\% Cl 1.4 to 6.1). A prolonged QTC interval on arrival was associated with a HR of $3.6(95 \% \mathrm{Cl} 1.0$ to 12.2$)$. Conclusion In the ED, a prolonged QTc interval in patients arriving with suspected poisoning seems to be associated with a threefold increased risk of 30-day all-cause mortality or cardiac arrest.

\section{INTRODUCTION}

Poisoning is a frequent cause of admission to the emergency department $(\mathrm{ED})^{12}$ and involves a variety of different drugs and substances. A wide range of drugs have been linked to QTc prolongation, ${ }^{3}$ which has been associated with all-cause mortality, cardiovascular death and sudden cardiac death. ${ }^{4-9}$ As an increased risk of mortality has been
Strengths and limitations of this study

- Patients were included from four different hospitals-two Swedish and two Danish.

- Propensity score matching was used to adjust for several confounders.

- Subgroups analysis was not possible due to a small number of events.

- The included ECGs were all automatic readouts, and the length of the QT interval was not confirmed manually.

documented in patients treated with potential QTc prolonging drugs, ${ }^{10-13}$ one may hypothesise that the risk is even higher among poisoned patients. Therefore, cardiac monitoring is recommended in patients poisoned by potentially proarrhythmic agents and drugs that can lead to torsades de pointes. ${ }^{14}$

Only few studies have investigated the relationship between QTc prolongation and adverse outcomes in a population of undifferentiated poisoned patients. ${ }^{15} 16$ The absolute and relative risk of mortality and cardiac arrest associated to QTc prolongation in poisoned patients remains unknown. Therefore, we aimed to: (1) describe the prevalence of QTc prolongation found among patients with suspected poisoning in the ED; and (2) to investigate if QTc prolongation is associated with an increased risk of mortality or cardiac arrest within 30 days after arrival to the ED.

\section{MATERIALS AND METHODS}

Study design and setting

This is a register-based cohort study. The study is based on ED data from 1 January 2010 to 
31 December 2014 from two Swedish hospitals (Skåne University Hospital, Lund, and Helsingborg Hospital) and from two Danish hospitals (Odense University Hospital and the Hospital of South West Jutland, Esbjerg) from 1 March 2013 to 30 April 2014. In both Denmark and Sweden, the healthcare systems are tax-funded, and all residents have free access to healthcare. The University Hospital Skåne has a contingency population of approximately 310 000, whereas Odense University Hospital covers a population of 290000 people. The two regional hospitals have a contingency population of 250000 people (Helsingborg) and 220000 people (Esbjerg).

\section{Selection of participants}

We identified all adults ( $\geq 18$ years) who arrived to the EDs with suspected poisoning. The contacts were eligible for the main analysis if they had a 12-lead ECG recorded within 4 hours after arrival. A missing QTc interval on the recorded ECG or a QRS duration of $\geq 120 \mathrm{~ms}$ were both reasons for exclusion. Patients with multiple contacts were included only at their first contact with suspected poisoning within the study period. Information regarding identification of patients with suspected poisoning is outlined in online supplementary appendix A.

\section{Data sources}

In both Denmark and Sweden, all residents have a unique personal civil registration number, which allows cross-linkage at personal level between databases. We extracted data from several registries: the logistic systems in the ED at the Region of Southern Denmark ${ }^{17}$ and Region of Skåne, the electronic central ECG databases at Region of Southern Denmark and Region of Skåne, the Danish National Patient Registry ${ }^{18}$ and Region of Skåne Healthcare databases, the Danish National Prescription Registry, ${ }^{19}$ the Swedish Pharmacy Registry, ${ }^{20}$ and finally The Danish Civil Registration System ${ }^{21}$ and the Swedish Population Register. ${ }^{22}$ Further information regarding the data sources is provided in online supplementary appendix A.

\section{ECG measurements and definitions}

The QT interval was measured at the first ECG recorded after contact to the ED. All the QT intervals were calculated automatically as a median value and stored in either MUSE Cardiology Information System (GE Healthcare) or Philips Diagnostic ECG. The GE Marquette 12SL ECG Analysis Program provided QTc intervals for ECGs recoded in MUSE. ${ }^{23}$ ECGs recorded by Phillips were analysed by the DXL-algorithm. ${ }^{24}$ Only QT intervals corrected for heart rate (QTc) was used in our analysis. For correction, we chose the Framingham Formula $\left(\mathrm{QTc}_{\text {Framing. }}\right.$ ham $=\mathrm{QT}+0.154(1-\mathrm{RR})) .{ }^{25}$ Additional details about ECG measurements are outlined in online supplementary appendix B.

\section{Exposure and outcome}

Our primary outcome was a combined endpoint of all-cause mortality or cardiac arrest (defined in online supplementary appendix C.1) within 30 days from the day of arrival to the ED. All patients were followed for 30 days, including those transferred to another department. Patients who died in relation to cardiac arrest were classified as dead rather than cardiac arrests. The primary exposure was QTc prolongation, defined as a QTc of $\geq 450 \mathrm{~ms}$ for men and $\geq 460 \mathrm{~ms}$ for women. ${ }^{26}$ Patients with a normal QTc length were defined as having a QTC interval of $<450 \mathrm{~ms}$ (men) or $<460 \mathrm{~ms}$ (women).

\section{Analysis}

The prevalence of QTc prolongation overall and in relation to specific groups of poisoning was described in a cross-sectional description. In this description, we identified all patients with a discharge diagnosis of poisoning (International Classification of Diseases (ICD-10) codes T36*-T65*, F100*, F110*, F120*, F130*, F140*, F150*, F160*, F170*, F180* or F190* as a primary or secondary diagnosis). All patients, who had a discharge diagnosis of poisoning, were subdivided into five poisoning groups: (1) analgesics and drugs of abuse, (2) psychotropic drugs including drugs affecting the central nervous system, (3) organic and chemical substances, non-medical, (4) others and (5) multidrug (see online supplementary appendix C.2).

The association between QTc prolongation and all-cause mortality and cardiac arrest was evaluated using propensity score matching. ${ }^{27} 28$ We calculated a propensity score for all included patients by use of logistic regression with QTc $\geq 450 \mathrm{~ms}$ (men) or $\geq 460 \mathrm{~ms}$ (women) as the outcome (binary outcome). Patients with a QTc interval between 440-449 ms (men) and 440-459 ms (women) were excluded in the model to avoid near-overlapping ranges. The following possible confounders were included in the propensity score model: sex, age, comorbidity (measured as Charlson Comorbidity Index ${ }^{29}{ }^{30}$ ), history of myocardial infarction or congestive heart failure (online supplementary appendix C.3 and C.4), prescription of QT prolonging drugs within 90 days (defined in online supplementary appendix C.5), ${ }^{31}$ heart rate and study centre. We performed a 1:2 parallel balanced nearest neighbour matching without replacement and with a calliper of $0.05 .^{32}$ In the matched cohorts, 30-day mortality was modelled using Cox regression.

\section{Statistics}

The absolute risk of event in patients with suspected poisoning was calculated overall, for those with QTC prolongation and for those without QTc prolongation. In the propensity score matched cohort, the risk associated with QTc prolongation was estimated as HRs. We estimated 95\% CIs based on a binominal distribution. To illustrate the impact of QTc prolongation on 30-day all-cause mortality or cardiac arrest, we generated a Kaplan-Meier failure curve.

In a sensitivity analysis, we restricted the material to individuals who were both suspected of being poisoned 
on arrival and received a discharge diagnose of poisoning. The prevalence of QTc prolongation and the propensity score analyses were repeated using the Bazett formula for QT correction. ${ }^{33}$

Statistical analyses were performed using STATA V.14.

The study was approved by the Danish Data Protection Agency (no. 2008-58-0035, journal nr. 15/21632) and The Danish Health Authority (no. 3-3013-1031).

\section{Patient and public involvement}

This was a study without contact to patients. All information was obtained through registers.

\section{RESULTS}

\section{Characteristics of the study cohort}

At the four hospitals, we identified a total of 6838 ED contacts with suspected poisoning. After exclusion of those aged $<18$ years $(n=22)$, an ECG not recorded in an acceptable time-interval $(n=1411)$, multiple contacts within the study period $(n=1412)$, a missing QT interval $(\mathrm{n}=1)$ or QRS duration $\geq 120 \mathrm{~ms} \quad(\mathrm{n}=123)$, the final cohort comprised 3869 patients with suspected poisoning (48.0\% men, median age 38 ) (figure 1). Of these, $69.2 \%$ $(n=2676)$ had a discharge diagnose of poisoning.

Patients with a prolonged QTc interval were older, had more comorbidity and more commonly had a history of heart disease than those without QTc prolongation (table 1).

In addition, prescription of QT-prolonging drugs was more frequent in the group with a prolonged QTc interval. Among patients with a redeemed prescription of a single QT-prolonging drug, 7.5\% had a prolonged QTc interval, whereas $8.8 \%$ of those taken two or more QT-prolonging drugs had a prolonged QTc interval. Among the included

Figure 1 Flow chart of the study population. ED, emergency department; QTc interval, corrected QT interval. 
Table 1 Baseline characteristics of the study population

\begin{tabular}{|c|c|c|c|c|c|}
\hline & \multirow[b]{3}{*}{ All $^{*}$} & \multicolumn{2}{|c|}{$\begin{array}{l}\text { Before propensity score } \\
\text { matching }\end{array}$} & \multicolumn{2}{|c|}{ After propensity score matching } \\
\hline & & QTC & Prolonged QTC & QTc & Prolonged QTC \\
\hline & & $\begin{array}{l}<440 \text { ms (men } \\
\text { and women) }\end{array}$ & $\begin{array}{l}\geq 450 \mathrm{~ms} \text { (men) } \\
\geq 460 \mathrm{~ms} \\
\text { (women) }\end{array}$ & $\begin{array}{l}<440 \mathrm{~ms} \text { (men } \\
\text { and women) }\end{array}$ & $\begin{array}{l}\geq 450 \mathrm{~ms} \text { (men) } \\
\geq 460 \mathrm{~ms} \text { (women) }\end{array}$ \\
\hline $\mathrm{N}$ & 3869 & 3296 & 253 & 496 & 248 \\
\hline Male (\%) & $1859(48.0)$ & $1634(49.6)$ & $121(47.8)$ & 229 (46.2) & $119(48.0)$ \\
\hline Age (median, IQR) & $38(25-53)$ & $36(24-51)$ & $52(36-68)$ & $53(37-69)$ & $51(35-66)$ \\
\hline $18-50, \mathrm{n}(\%)$ & $2747(71.0)$ & $2444(74.2)$ & $119(47.0)$ & $236(48.0)$ & $119(48.0)$ \\
\hline $51-69, \mathrm{n}(\%)$ & $788(20.4)$ & $611(18.5)$ & $77(30.4)$ & $140(28.5)$ & $77(31.0)$ \\
\hline $\mathrm{CCl}=1$ & $718(18.6)$ & $587(17.8)$ & $60(23.7)$ & $133(26.8)$ & $58(23.4)$ \\
\hline $\mathrm{CCl} \geq 2$ & $404(10.4)$ & $314(9.5)$ & $53(20.9)$ & $100(20.2)$ & $50(20.2)$ \\
\hline $\begin{array}{l}\text { Myocardial infarction or congestive } \\
\text { heart failure, } \mathrm{n}(\%)\end{array}$ & $185(4.8)$ & $136(4.1)$ & $32(12.6)$ & $55(11.1)$ & $29(11.7)$ \\
\hline QT-prolonging drugs, n (\%) & $1518(39.2)$ & $1248(37.9)$ & $110(43.5)$ & $213(42.9)$ & $109(44.0)$ \\
\hline \multicolumn{6}{|l|}{ ECG measurements } \\
\hline Heart rate (median, IQR) & $85(73-99)$ & $87(74-101)$ & $76(65-84)$ & $76(65-87)$ & $76(65-85)$ \\
\hline QTc $\geq 500 \mathrm{~ms}, \mathrm{n}(\%)$ & $27(0.7)$ & - & $27(10.7)$ & - & 27 (10.9) \\
\hline Any diagnose of poisoning, $n(\%)$ & $2676(69.2)$ & $2282(69.2)$ & $153(60.5)$ & $310(62.5)$ & $151(60.9)$ \\
\hline 4. Others & $470(17.6)$ & $392(17.2)$ & $30(19.6)$ & $54(17.4)$ & $29(19.2)$ \\
\hline 5. Multidrug & $502(18.8)$ & $425(18.6)$ & $29(19.0)$ & $62(20.0)$ & $28(18.5)$ \\
\hline \multicolumn{6}{|l|}{ Clinics, n (\%) } \\
\hline $\begin{array}{l}\text { The University Hospital Skåne, } \\
\text { Lund }\end{array}$ & $1794(46.4)$ & $1539(46.7)$ & $125(49.4)$ & $247(49.8)$ & $124(50.0)$ \\
\hline Odense University Hospital & $501(12.9)$ & $419(12.7)$ & $28(11.1)$ & $50(10.1)$ & $28(11.3)$ \\
\hline Helsingborg Hospital & $1372(35.5)$ & $1176(35.7)$ & $81(32.0)$ & $170(34.3)$ & $79(31.9)$ \\
\hline Hospital of South West Jutland & $202(5.2)$ & $162(4.9)$ & $19(7.5)$ & $29(5.8)$ & $17(6.9)$ \\
\hline
\end{tabular}

*In the total cohort patients with a near-overlapping QTc interval (440-449 ms men, 440-459 ms women) are included ( $\mathrm{n=320).}$

$\mathrm{CCl}$, Charlson Comorbidity Index.

patients, $6.5 \%$ (95\% CI 5.9 to 7.4 ) had QTc prolongation, while the prevalence of severe QTc prolongation $(\geq 500$ $\mathrm{ms}$ ) was $0.7 \%$ (95\% CI 0.5 to 1.0 ). The prevalence of QTc prolongation in relation to specific groups of poisoning varied within the range $4.8 \%-6.2 \%$, with the highest prevalence in the group categorised as 'others' $(6.2 \%$; $95 \% \mathrm{CI}$ 4.8 to 8.7 ) (table 2 ).

\section{Prognosis}

Overall, the 30-day risk of all-cause mortality or cardiac arrest was $0.8 \%$ (95\% CI $0.6 \%$ to $1.2 \%, \mathrm{n}=32$ ). Among individuals with QTc prolongation $(\mathrm{n}=253)$, death within 30 days after contact to the ED occurred in seven patients, whereas one patient suffered from cardiac arrest. Among those with a normal QTc interval $(\mathrm{n}=3616)$, we found 24 
Table 2 QTC prolongation in relation to poisoning groups

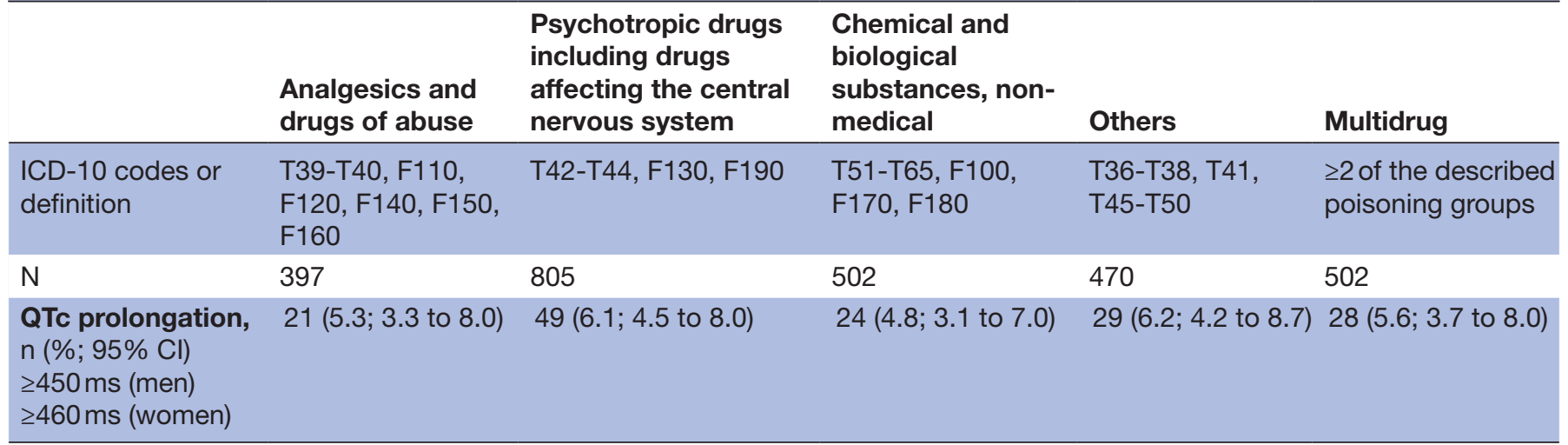

ICD-10, International Classification of Diseases, 10th Revision.

events during the follow-up period. The absolute risk of event within 30 days was $3.2 \%$ (95\% CI 1.4 to 6.1 ) and $0.7 \%$ (95\% CI 0.5 to 1.0$)$ for patients with and without QTc prolongation, respectively.

The propensity score analysis included 248 patients with a QTc of $\geq 450 \mathrm{~ms}$ (men) or $\geq 460 \mathrm{~ms}$ (women) matched with 496 patients with a QTc interval $<440 \mathrm{~ms}$. Acceptable balance of baseline variables was achieved (table 1). QTc prolongation was associated with a HR of 3.6 (95\% CI 1.0 to 12.2) for 30-day all-cause mortality or cardiac arrest (table 3 and figure 2 ).

\section{Subgroups and sensitivity analyses}

Our results from the subgroup analysis are outlined in online supplementary appendix D. When restricting to those who also received a discharge diagnose of poisoning,

\begin{tabular}{|c|c|c|c|}
\hline \multicolumn{4}{|c|}{ Propensity score matched cohort } \\
\hline & $\mathbf{n}$ & $\begin{array}{l}\text { Events } \\
\text { (no.) }\end{array}$ & $\mathrm{HR}^{*}(95 \% \mathrm{Cl})$ \\
\hline \multicolumn{4}{|l|}{ Suspected poisoning } \\
\hline $\begin{array}{l}\text { Normal QTc interval } \\
<440 \mathrm{~ms}\end{array}$ & 496 & $\mathrm{n}<5$ & 1.0 (ref) \\
\hline $\begin{array}{l}\text { QTc prolongation } \\
\geq 450 \mathrm{~ms} \text {, men } \\
\geq 460 \mathrm{~ms} \text {, women }\end{array}$ & 248 & 8 & 3.6 (1.0 to 12.2$)$ \\
\hline \multicolumn{4}{|l|}{ Diagnose of poisoning $†$} \\
\hline $\begin{array}{l}\text { Normal QTc interval } \\
<440 \mathrm{~ms}\end{array}$ & 310 & $\mathrm{n}<5$ & 1.0 (ref) \\
\hline $\begin{array}{l}\text { QTc prolongation } \\
\geq 450 \mathrm{~ms} \text {, men } \\
\geq 460 \mathrm{~ms} \text {, women }\end{array}$ & 151 & 6 & 10.5 (1.2 to 90.0$)$ \\
\hline
\end{tabular}

${ }^{*}$ Cox regression calculated after $1: 2$ propensity score matching comparing patients with QTc prolongation to patients without QTc prolongation. In this population, patients with nearoverlapping ranges of the QTc interval were excluded (QTC 440-449 ms, men and 440-459 ms, women).

†Patient who arrived with suspected poisoning and had a discharge diagnose of poisoning.

If the number of events in the analysis was less than 5 (marked by $n<5$ ), the number of patients in the strata is not shown. we found an overall 30-day risk of $0.7 \%$ (95\% CI 0.4 to 1.1), and QTc prolongation yielded an overall HR of 10.5 (95\% CI 1.2 to 90.0$)$. When we corrected the QT interval with the Bazett formula, a total of 1112 patients had QTc prolongation $(28.7 \%)$, which was associated with a HR of $1.0(95 \%$ CI 0.2 to 5.5$)$.

\section{DISCUSSION}

In this transnational cohort of patients with suspected poisoning arriving to the ED, QTc prolongation was common $(6.5 \%)$. A prolonged QTc interval was associated with a threefold increased risk of 30-day all-cause mortality or cardiac arrest and an absolute risk of $3.2 \%$.

This study has several strengths. First, this was a multicentre cohort study with data from two Swedish and two Danish EDs, which ensured a broad representability. Use of personal identification numbers in all contacts to the hospital system in Sweden and Denmark provides the possibility to follow individual patients in and out of hospital, and loss of follow-up or unmeasured registration of death did not occur. ${ }^{17-22}$ In addition, we implemented several

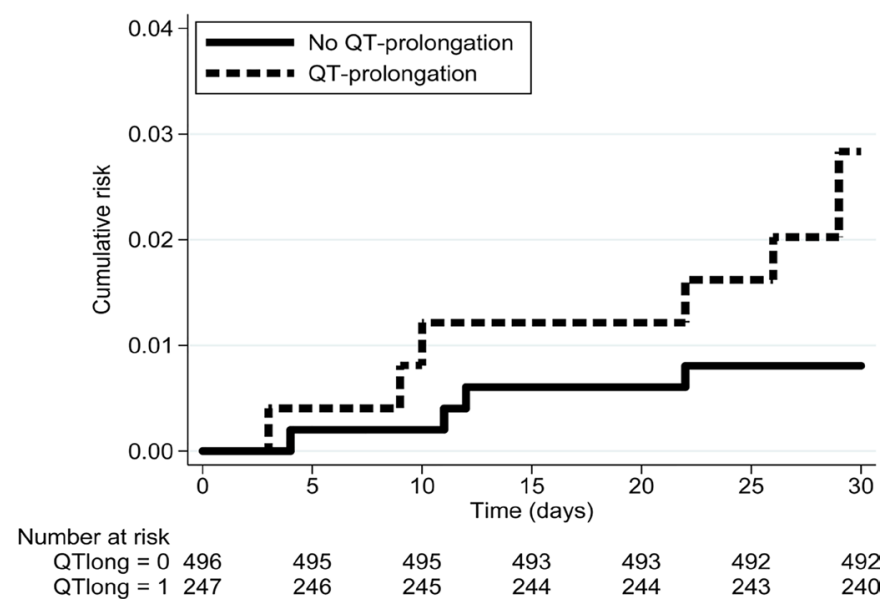

Figure 2 Kaplan-Meier failure estimate. QTclong=0, patients without QTc prolongation; QTclong=1, patients with QTc prolongation. 
confounders in our propensity score model, and thus managed to control for these despite a low event rate. We included patients who were suspected for being poisoned on arrival to the ED. These patients do-in contrast to patients identified by their discharge diagnosis-represent the clinical situation at the door in the ED. At this point, the doctors have to decide whether to observe the patients using telemetry.

This study also has several limitations. First of all, the design was an observational design. The ECG measures were all automatic readouts, and we did not manually validate the length of the QT intervals. However, this method has been validated in a previous Danish study using the same technique, which showed a good overall agreement between manual QTc interval and the digital record of the QTc interval with a mean difference of $1.3 \mathrm{~ms}^{8}{ }^{8}$ Furthermore, we did not exclude ECGs with diagnoses complicating QTc measuring, for example, atrial fibrillation. We did not have information regarding previous ECGs, and we do not know if some patients had a previous ECG with QTc prolongation before arrival with suspected poisoning. The dose of drug or substance was unknown, and we were ignorant of the timing of the ECG recording in relation to peak drug concentration. The poisonings were not confirmed by blood samples or by urine tests but were extracted from predefined ICD-10 codes. In addition, administration of diuretics and possible electrolyte imbalance were unknown.

The small number of events was a limitation in its own and did not allow for meaningful subgroup analysis. Since cardiac arrest was identified based on hospital registration, an eventually event of unregistered cardiac arrest, where the patient survived, is not included as an event. The number of these events is believed to be small as registration of cardiac arrest is mandatory in both the Swedish and Danish healthcare system. With a small number of events, any miscounting of events would lead to considerable change in risk estimates. If we have overlooked one event of cardiac arrest who survived in the group of patients with QTc prolongation, it would increase the absolute risk from $3.2 \%$ to $3.6 \%$, while the risk of event in the entire study population would increase from $0.8 \%$ to $0.9 \%$.

The event rate in our cohort $(0.8 \%)$ is in accordance with previous studies of poisoned patients $(0.5 \%-1.2 \%) .{ }^{16} 3435$ In contrast, the prevalence of QTc prolongation is substantially lower $(6.5 \%)$ than in a previous study of unselected ED patients $(35 \%) .{ }^{36}$ This is probably due to the choice of QT correcting formula. If the Bazett formula had been chosen for main analysis, the prevalence of QTc prolongation in our study population would have been $28.7 \%$. It is of broad consensus that the more widely used Bazett formula tends to overcorrect at heart rates at $80-90$ beats per minute and above resulting in a higher prevalence of QTc prolongation. ${ }^{33}$ As a high percentage of acute patients have tachycardia at arrival, this probably explains most of the difference between the occurrence of QTc prolongation in our study and in the study of unselected ED patients. The Framingham formula used in our study is considered superior compared with the more widely used Bazett formula. ${ }^{37}$

The clinical impact of our findings is the difference in risk of all-cause mortality and cardiac arrest within 30 days in respect to QTc prolongation. We found an absolute risk of $0.7 \%$ in patients with suspected poisoning without QTc prolongation, whereas patients with a prolonged QTc interval have an absolute risk of 3.2\%, which translates into an HR of 3.6 (95\% CI 1.0 to 12.2). In the general population, a meta-analysis reported a pooled relative risk of 1.35 (95\% CI 1.24 to 1.46) for long-term mortality in patients with QTc prolongation. ${ }^{7} \mathrm{~A}$ recent study including all patients who had an ECG recorded at the hospital for any reason reported QTc prolongation to be associated with a HR of 7.3 (95\% CI 4.10 to 13.05$)$ for 30-day mortality. ${ }^{37}$ Combined, these studies support the hypothesis that patients with a prolonged QTc are at increased risk. Whether this is directly linked to the increased QTc interval or due to other risk factors associated with a prolonged QTc remains unknown.

As demonstrated in our cohort, the prevalence of QTc prolongation is strongly associated to the correction formula. Furthermore, the difference between the HR calculated in the main analysis using Framingham (HR 3.6; 95\% CI 1.0 to 12.2 ) versus the sensitivity analysis using Bazett (HR 1.0; 95\% CI 0.2 to 5.5) is remarkable. We suspect that using the Bazett formula dilutes the association by including more patients at low risk as a result of overcorrection.

Despite the use of a propensity score model adjusting for several covariates, we cannot exclude residual confounding. From a clinical point of view, this means that the patients with a prolonged QTc probably need special care and attention. However, the needed care is not necessarily limited to telemetry and increased cardiac awareness. Of note, a ventricular arrhythmia with fatal outcome caused by drug-induced QTc prolongation would be expected to happen within a relatively short time-interval after exposure. This was not the case in our study with the first event occurring 3 days after contact (see figure 2). In addition, a QTc interval threshold for identification of patients in need of cardiac telemetry is not well established. Unfortunately, our cohort was too small to do further subdivisions of the QTc interval.

Ventricular arrhythmias, especially torsades de pointes, are feared consequences of QT prolongation and may be the cause of death in some poisonings. ${ }^{38}{ }^{39}$ However, as torsades de pointes is a rare condition, ${ }^{38}{ }^{39}$ it is unlikely to have influenced our results.

In this cohort of patients with suspected poisoning, $69.2 \%$ received a discharge diagnose of poisoning. This is in contrast to results from a previous Danish study, which found an agreement of $79 \%$ for suspected poisoning on arrival and a discharge diagnose of poisoning. ${ }^{17}$ In our cohort, only those who had an ECG recorded were included, and several common 
poisonings, for example, alcohol intoxication, are usually not followed by ECG recording.

QTc prolongation was most frequent in the group of poisoning labelled 'others' (table 2). In this group, the ICD-10 code T50.9 for unspecific poisonings was given to the majority of the patients. These patients might have been too sick to tell about their poisoning or perhaps denied to do so. This reflects a common clinical problem in the ED and indicates that a specific poisoning diagnosis can be difficult to establish. Furthermore, lack of precision in coding procedure may contribute to unspecific diagnoses.

In conclusion, we found QTc prolongation in a mixed population of patients with suspected poisoning in the ED of two Swedish and two Danish hospitals to be associated with a threefold risk of 30-day all-cause mortality or cardiac arrest and an absolute risk of $3.2 \%$.

Contributors CSH designed the study, interpreted the results and drafted the paper. AP analysed the data. All authors conceived the study. ATL, AP and HKJ provided statistical advice and advice on the study design. AP, ATL, HKJ, UE, MB, and JLF critically reviewed the paper, assisted with interpretation of the results and have approved the final edition. CSH takes responsibility for the final paper.

Funding This study was funded by an independent grant from The Research Foundation of Odense University Hospital.

Disclaimer The funding sources had no role in the design of the study, data analysis or interpretation of the results.

Competing interests ATL was supported by an unrestricted grant to the University of Southern Denmark from TrygFoundation.

Patient consent Not required.

Ethics approval In consistency with Swedish law the study was approved by the Regional Ethics Committee in Lund and by Region Skåne.

Provenance and peer review Not commissioned; externally peer reviewed.

Data sharing statement Due to Danish law regarding personal data, we are not allowed to share data in public dataset. However, we welcome every researcher who wants to repeat the analysis or do new analysis in the dataset. Please contact professor Annmarie Lassen (Annmarie.Lassen@rsyd.dk), and she will help the researcher to get access to the data.

Open access This is an open access article distributed in accordance with the Creative Commons Attribution Non Commercial (CC BY-NC 4.0) license, which permits others to distribute, remix, adapt, build upon this work non-commercially, and license their derivative works on different terms, provided the original work is properly cited and the use is non-commercial. See: http://creativecommons.org/ licenses/by-nc/4.0/

(C) Article author(s) (or their employer(s) unless otherwise stated in the text of the article) 2018. All rights reserved. No commercial use is permitted unless otherwise expressly granted.

\section{REFERENCES}

1. Carter-Storch R, Olsen UF, Mogensen CB. Admissions to emergency department may be classified into specific complaint categories. Dan Med J 2014:61:A4802.

2. Safwenberg U, Terént A, Lind L. Differences in long-term mortality for different emergency department presenting complaints. Acad Emerg Med 2008;15:9-16.

3. Woosley RL, Romero KA. QTdrugs List. AZCERT, Inc. 2016. https:// www.crediblemeds.org/new-drug-list/ (accessed 17 Dec 2015).

4. de Bruyne MC, Hoes AW, Kors JA, et al. Prolonged QT interval predicts cardiac and all-cause mortality in the elderly. The Rotterdam Study. Eur Heart J 1999;20:278-84.

5. Straus SM, Kors JA, De Bruin ML, et al. Prolonged QTc interval and risk of sudden cardiac death in a population of older adults. J Am Coll Cardiol 2006;47:362-7.
6. Robbins J, Nelson JC, Rautaharju PM, et al. The association between the length of the QT interval and mortality in the Cardiovascular Health Study. Am J Med 2003;115:689-94.

7. Zhang Y, Post WS, Blasco-Colmenares E, et al. Electrocardiographic QT interval and mortality: a meta-analysis. Epidemiology 2011;22:660-70.

8. Nielsen JB, Graff C, Rasmussen PV, et al. Risk prediction of cardiovascular death based on the QTc interval: evaluating age and gender differences in a large primary care population. Eur Heart $J$ 2014:35:1335-44.

9. Panoulas VF, Toms TE, Douglas KM, et al. Prolonged QTC interval predicts all-cause mortality in patients with rheumatoid arthritis: an association driven by high inflammatory burden. Rheumatology 2014:53:131-7.

10. Straus SM, Sturkenboom MC, Bleumink GS, et al. Non-cardiac QTCprolonging drugs and the risk of sudden cardiac death. Eur Heart $J$ 2005;26:2007-12.

11. Ray WA, Chung CP, Murray KT, et al. Atypical antipsychotic drugs and the risk of sudden cardiac death. N Engl J Med 2009;360:225-35.

12. Ray WA, Meredith S, Thapa PB, et al. Cyclic antidepressants and the risk of sudden cardiac death. Clin Pharmacol Ther 2004; $75: 234-41$.

13. Ray WA, Murray KT, Hall K, et al. Azithromycin and the risk of cardiovascular death. N Engl J Med 2012;366:1881-90.

14. Drew BJ, Califf RM, Funk M, et al. Practice standards for electrocardiographic monitoring in hospital settings: an American Heart Association scientific statement from the Councils on Cardiovascular Nursing, Clinical Cardiology, and Cardiovascular Disease in the Young: endorsed by the International Society of Computerized Electrocardiology and the American Association of Critical-Care Nurses. Circulation 2004:110:2721-46.

15. Manini AF, Nelson LS, Skolnick AH, et al. Electrocardiographic predictors of adverse cardiovascular events in suspected poisoning. J Med Toxicol 2010;6:106-15.

16. Manini AF, Hoffman RS, Stimmel B, et al. Clinical risk factors for in-hospital adverse cardiovascular events after acute drug overdose. Acad Emerg Med 2015;22:499-507.

17. Nørgaard B, Mogensen CB, Teglbjærg LS, et al. Diagnostic packages can be assigned accurately in emergency departments. A multicentre cohort study. Dan Med J 2016;63:A5240.

18. Schmidt M, Schmidt SA, Sandegaard JL, et al. The Danish National Patient Registry: a review of content, data quality, and research potential. Clin Epidemiol 2015;7:449-90.

19. Pottegård $\mathrm{A}$, Schmidt SAJ, Wallach-Kildemoes $\mathrm{H}$, et al. Data resource profile: the danish national prescription registry. Int $J$ Epidemiol 2017;46:dyw213.

20. Astrand B, Hovstadius B, Antonov K, et al. The Swedish National Pharmacy Register. Stud Health Technol Inform 2007;129(Pt 1):345-9.

21. Schmidt M, Pedersen L, Sørensen HT. The Danish Civil Registration System as a tool in epidemiology. Eur J Epidemiol 2014;29:541-9.

22. Ludvigsson JF, Otterblad-Olausson P, Pettersson BU, et al. The Swedish personal identity number: possibilities and pitfalls in healthcare and medical research. Eur J Epidemiol 2009;24:659-67.

23. MarquetteTM 12SLTM ECG Analysis Program. Physician's Guide. 2056246-002 Revision B. Milwaukee, WI: GE Healthcare, 2015.

24. Läkarhandbok för Phillips DXL-algoritm för EKG. Publikationsnummer 453564149891. Andover, MA: Phillips Medical Systems, 2009.

25. Sagie A, Larson MG, Goldberg RJ, et al. An improved method for adjusting the QT interval for heart rate (the Framingham Heart Study). Am J Cardiol 1992;70:797-801.

26. Rautaharju PM, Surawicz B, Gettes LS, et al. AHA/ACCF/HRS recommendations for the standardization and interpretation of the electrocardiogram: part IV: the ST segment, T and U waves, and the QT interval: a scientific statement from the American Heart Association Electrocardiography and Arrhythmias Committee, Council on Clinical Cardiology; the American College of Cardiology Foundation; and the Heart Rhythm Society: endorsed by the International Society for Computerized Electrocardiology. Circulation 2009:119:e241-e250.

27. Stürmer T, Joshi M, Glynn RJ, et al. A review of the application of propensity score methods yielded increasing use, advantages in specific settings, but not substantially different estimates compared with conventional multivariable methods. J Clin Epidemiol 2006;59:437.e1-437.e24.

28. Rassen JA, Shelat AA, Myers J, et al. One-to-many propensity score matching in cohort studies. Pharmacoepidemiol Drug Saf 2012;21 Suppl 2(Suppl 2):69-80.

29. Charlson ME, Pompei P, Ales KL, et al. A new method of classifying prognostic comorbidity in longitudinal studies: development and validation. J Chronic Dis 1987:40:373-83. 
30. Quan $\mathrm{H}$, Sundararajan V, Halfon P, et al. Coding algorithms for defining comorbidities in ICD-9-CM and ICD-10 administrative data. Med Care 2005;43:1130-9.

31. Poluzzi E, Raschi E, Diemberger I, et al. Drug-induced arrhythmia: bridging the gap between pathophysiological knowledge and clinical practice. Drug Saf 2017;40:461-4.

32. Austin PC. Optimal caliper widths for propensity-score matching when estimating differences in means and differences in proportions in observational studies. Pharm Stat 2011;10:150-61.

33. Bh C. An analysis of time-relations of electrocardiograms. Heart 1920;7:353-70.

34. Manini AF, Nelson LS, Stimmel B, et al. Incidence of adverse cardiovascular events in adults following drug overdose. Acad Emerg Med 2012;19:843-9.
35. Gunnell D, Ho D, Murray V. Medical management of deliberate drug overdose: a neglected area for suicide prevention? Emerg Med $J$ 2004;21:35-8.

36. Seftchick MW, Adler PH, Hsieh M, et al. The prevalence and factors associated with QTc prolongation among emergency department patients. Ann Emerg Med 2009;54:763-8.

37. Vandenberk B, Vandael E, Robyns T, et al. Which QT correction formulae to use for QT monitoring? J Am Heart Assoc 2016;5:e03264.

38. Al-Abri SA, Woodburn C, Olson KR, et al. Ventricular dysrhythmias associated with poisoning and drug overdose: a 10-year review of statewide poison control center data from California. Am J Cardiovasc Drugs 2015;15:43-50.

39. Yap YG, Camm AJ. Drug induced QT prolongation and torsades de pointes. Heart 2003;89:1363-72. 